\title{
Influência dos Modelos de Alfred e de Andreasen Sobre a Microestrutura e Densidade a Verde de Compactos Cerâmicos Obtidos por Colagem ou Prensagem
}

\section{(The Influence of Alfred and Andreasen Models on the Microstructure and Green Density of Ceramic Compacts Obtained by Slip Casting and Dry Pressing)}

\author{
Fernando dos Santos Ortega, \\ Rafael Giuliano Pileggi, \\ Pilar Sepúlveda, \\ Victor Carlos Pandolfelli \\ Departamento de Engenharia de Materiais, DEMa-UFSCAR \\ Rodovia Washington Luis, km 235 - CP 676, CEP 13565-905, São Carlos, SP, Brazil \\ e-mail:vicpando@power.ufscar.br
}

\section{Resumo}

A densidade de empacotamento de pós cerâmicos pode ser maximizada mediante o uso de modelos teóricos de distribuição de tamanho de partículas, o que pode resultar em importantes efeitos no comportamento reológico de suspensões, e em sensível aumento na densidade a verde dos compactos. Neste trabalho, foram estudadas propriedades de pós com distribuição de tamanho de partícula segundo os modelos de Alfred e de Andreasen em compactos obtidos por prensagem uniaxial, isostática e por colagem de barbotina. Verificou-se que embora o modelo de Alfred seja mais bem fundamentado que o de Andreasen, proporcionou compactos de menor densidade e pouca homogeneidade, nas amostras obtidas por colagem. Este comportamento foi atribuído à estrutura de poros do compacto, a qual possibilitou o arraste de partículas finas pelo fluxo de água. Nas amostras com distribuição segundo o modelo de Andreasen, isto não foi verificado.

\section{INTRODUÇÃO}

O princípio do empacotamento de partículas consiste basicamente na seleção de tamanhos adequados de partículas, e no proporcionamento entre as quantidades desses tamanhos, visando obter compactos com densidade controlada [1].

Os conhecimentos sobre empacotamento de partículas têm sido utilizados em diversos tipos de processamento cerâmico, uma vez que proporcionam importantes propriedades aos compactos. Distribuições de tamanho de partículas que favorecem a obtenção de compactos densos apresentam algumas vantagens em relação a estruturas com menor grau de empacotamento, como menor retração

\section{Abstract}

The use of theoretical models of particle size distribution to maximise the packing density of a powder may result in significant improvement of the rheological behaviour of suspensions and compact's green density. In this work, Alfred and Andreasen models were studied, taking into account their effect on the characteristics of compacts obtained by uniaxial and isostatic pressing and by slip casting. It was noticed that although the Alfred model is considered more realistic than the Andreasen model, it has led to less dense and less homogeneous compacts in the samples obtained by slip casting. This behaviour, which hasn't been noticed in samples obtained by dry pressing, was attributed to the pore structure of the compacts, which allowed water flow to drag fine particles. In samples obtained according to the Andreasen model, that was not observed.

durante a queima e melhor sinterabilidade, já que os poros na estrutura são menores, podendo ser eliminados mais facilmente. A obtenção de materiais isentos de macroporos e portanto com maior resistência mecânica é também favorecida. Além disso, a distribuição granulométrica afeta diretamente o comportamento reológico de suspensões, e quando adequada, permite conciliar alto teor de sólidos com baixa viscosidade [2]. Pode-se controlar ainda o tamanho e formato de poros intersticiais do compacto, de modo a se obter velocidades de secagem e permeabilidade mais elevadas, o que em geral é conseguido em estruturas com baixa densidade de empacotamento.

Em linhas gerais, um empacotamento denso de partículas 
consiste em uma estrutura de partículas grandes cujos interstícios são preenchidos por partículas menores, criando novos interstícios que serão preenchidos por partículas ainda menores, e assim sucessivamente. Este empacotamento é diretamente influenciado por alguns fatores, como a correta seleção de tamanhos, o formato e a rugosidade superficial das partículas.

Diversos modelos matemáticos de distribuição de tamanho de partículas foram criados com o intuito de maximizar a densidade de empacotamento dos compactos. Dentre estes, os modelos de Alfred [3] e Andreasen [3] estão entre os mais conhecidos.

O modelo de Andreasen foi baseado em uma condição de similaridade entre partículas grandes e partículas menores distribuídas ao seu redor, a qual pôde ser relacionada a uma série de potências resultando na seguinte equação:

$$
\frac{\mathrm{CPFT}}{100}=\left(\frac{\mathrm{D}}{\mathrm{D}_{\mathrm{L}}}\right)^{\mathrm{q}}
$$

onde: $\mathrm{CPFT}=$ Porcentagem acumulada de partículas menores que o tamanho D;

$\mathrm{D}=$ diâmetro da partícula;

$\mathrm{D}_{\mathrm{L}}=$ Tamanho da maior partícula do sistema;

$\mathrm{q}=$ módulo de distribuição.

Simulações computacionais realizadas posteriormente [3] mostraram que um valor de $\mathrm{q}=0,37$ é o que proporciona a máxima densidade de empacotamento.

O modelo de Andreasen admite que em uma distribuição existem partículas sucessivamente menores, e assume que a inexistência de um diâmetro mínimo de partícula, em que CPFT se iguala a zero, não altera significativamente a densidade de empacotamento.

Posteriormente, Dinger e Funk [3] reconheceram que a inexistência de partículas infinitamente pequenas podia acarretar desvios significativos no empacotamento de partículas previsto. Deste modo, incorporando ao modelo de Andreasen um valor mínimo de tamanho de partícula, que é uma característica de sistemas reais, desenvolveram o modelo de Alfred, expresso pela seguinte equação:

$$
\frac{C P F T}{100}=\left(\frac{D^{q}-D_{s}^{q}}{D_{L}^{q}-D_{s}^{q}}\right)
$$

onde $\mathrm{D}_{\mathrm{S}}$ é o diâmetro da menor partícula do sistema.

Nota-se que se o valor de $D_{S}$ for igual a zero, a equação se reduz ao modelo de Andreasen. A equação de Alfred é considerada atualmente o modelo de empacotamento de partículas mais adequado a sistemas reais.

Os modelos descritos têm sido utilizados com relativo sucesso no processamento cerâmico. No caso específico da colagem de barbotina, entretanto, há algumas divergências sobre o efeito da distribuição de tamanho de partículas na produção de suspensões com baixa viscosidade e alta velocidade de formação de parede, produzindo compactos densos. Estudos envolvendo o uso do modelo de Alfred neste tipo de processamento [4] ainda não levaram a resultados conclusivos.

Neste trabalho, buscou-se analisar a densidade a verde e a distribuição de tamanho de poros proporcionada pelos modelos de Alfred e de Andreasen em compactos obtidos por processos de conformação via úmido (colagem de barbotina) e a seco (prensagem uniaxial e isostática). Ênfase foi dada à colagem, para a qual observou-se o efeito da distribuição granulométrica sobre a velocidade de formação de parede e a densidade do compacto.

\section{MATERIAIS E MÉTODOS}

Para investigar-se o efeito da distribuição de tamanho de partículas sobre o empacotamento, a velocidade de formação de parede e a microestrutura dos compactos obtidos, foram efetuadas as seguintes etapas:

\section{Preparação de Pós com Distribuições Granulométricas-Alvo}

O estudo da influência da distribuição de tamanho de partícula sobre as propriedades de suspensões foi realizado tomando-se como base os modelos de Andreasen (eq. A) e Alfred (eq. B), considerando-se um módulo de distribuição (q) igual a 0,37 , para proporcionar a maior densidade de empacotamento.

Para conseguir-se as curvas com as distribuições granulométricas desejadas, efetuou-se a moagem, em moinho de bolas, de uma alumina eletrofundida marrom (ALCOA EC31R - 96,7\% $\mathrm{Al}_{2} \mathrm{O}_{3}, 2,4 \% \mathrm{TiO}_{2}, 0,6 \% \mathrm{SiO}_{2}, 0,3 \% \mathrm{Fe}_{2} \mathrm{O}_{3}$ ) por tempos de 1,$5 ; 3 ; 8 ; 21 ; 99$ e 144 horas. Esta matéria-prima foi escolhida por praticamente não sofrer alteração morfológica ao longo da moagem além de ser amplamente utilizada em concretos refratários. Foi utilizada uma relação água:bola:alumina de 4:5:1, em quantidade suficiente para preencher o moinho até aproximadamente a metade de seu volume. No decorrer da moagem, foram adicionadas pequenas quantidades de poliacrilato de sódio para evitar o aumento na viscosidade devido à cominuição das partículas. Cuidou-se, entretanto que as adições de defloculante nunca ultrapassassem o ponto de mínima viscosidade, o qual foi estimado em ensaios preliminares.

Os pós obtidos após estas moagens foram secos em estufa a $100^{\circ} \mathrm{C}$ e desaglomerados com o auxílio de almofariz e peneira \#100 mesh $(150 \mu \mathrm{m})$. Na seqüência, fez-se a caracterização das distribuições de tamanho de partícula (Sedigraph 5100) dos pós obtidos, após a eliminação de aglomerados fracos com o auxílio de ultra-som. Feita a caracterização, foi utilizado o software PSDesigner, desenvolvido por este grupo de pesquisa, o qual sistematiza uma metodologia para obtenção de pós com distribuição granulométrica dada por uma curvaalvo. Isso é conseguido com a divisão da curva de distribuição acumulada de cada matéria-prima em intervalos discretos de tamanho de partícula. Somando-se a quantidade de pó fornecida por cada matéria-prima dentro de cada intervalo discreto, calculam-se as diferentes proporções com que estas devem ser combinadas para se obter a distribuição mais próxima possível a uma curva-alvo.

Assim, tendo-se em vista as curvas-alvo de Alfred e Andreasen com coeficiente de distribuição igual a 0,37 , foi calculada a melhor proporção entre as matérias-primas obtidas, de modo a obter-se a máxima aproximação possível às curvas teóricas. A melhor combi- 
nação foi identificada minimizando-se o desvio quadrático médio entre a curva experimental e a curva dada pela equação.

\section{Estudo das Propriedades das Composições}

As composições preparadas, com distribuição granulométrica segundo os modelos de Alfred e Andreasen, foram caracterizadas quanto à distribuição de tamanho de partícula (Sedigraph - 5100) e área superficial específica (Micromeritics - ASAP 2010).

Com as curvas obtidas, empregou-se o procedimento matemático desenvolvido por Yu e Standish [7], o qual determina a porosidade residual de um compacto a partir de sua distribuição granulométrica. A porosidade calculada através deste procedimento permite avaliar teoricamente qual seria a máxima densidade de empacotamento possível para um compacto, a partir de sua distribuição de tamanho de partícula. No presente caso, a rotina proposta para a execução dos cálculos foi automatizada através de um programa em C++.

Com as composições obtidas, foram preparadas suspensões com densidade $2,6 \mathrm{~g} / \mathrm{cm}^{3}$ (55\% em volume de sólidos), às quais adicionou-se a quantidade necessária de poliacrilato de sódio para atingir a viscosidade mínima. Foi feita a dispersão com ultra-som, e em seguida foram preenchidos moldes cilíndricos constituídos de tubos de PVC de $3 / 4$ de polegada e $5 \mathrm{~cm}$ de altura conectados pela base a um bloco de gesso, de consistência $65 \%$ e tamanho suficiente para não ficarem saturados com a umidade absorvida no decorrer da colagem. Os blocos de gesso foram todos extraídos de uma mesma placa, garantindo homogeneidade na pressão de sucção.

Este sistema possibilitou uma colagem de barbotina uniaxial. Cada amostra foi colada em um molde novo, evitando-se efeitos que possam ser atribuídos à degradação do molde, ou à obstrução de seus capilares por partículas muito finas. As dimensões do molde foram grandes o suficiente para evitar que ocorresse saturação dos mesmos no decorrer do tempo, o que poderia diminuir a pressão de capilaridade, prejudicando a análise dos resultados. As colagens se estenderam por tempos de 3, 6, 10, 15 e 20 minutos, proporcionando tortas de diferentes alturas. Com isso, foi possível avaliar a velocidade de formação de parede para as diferentes composições. As pastilhas obtidas foram secas por 24 horas em temperatura ambiente e mais 24 horas a $110^{\circ} \mathrm{C}$.

Foram também produzidas pastilhas por prensagem uniaxial dos pós, a pressões de $91 \mathrm{MPa}$ e $136 \mathrm{MPa}$, e por prensagem isostática a 200 MPa. Para isso, adicionou-se ao pó $4 \%$ em peso de água e $0,5 \%$ em peso de lignossulfonato de sódio como agente ligante e lubrificante.

Os corpos-de-prova foram caracterizados quanto à distribuição de tamanho de poro (Micromeritics - Poresizer 9320) e densidade aparente pelo método de Arquimedes, em querosene, de acordo com a norma NBR-6220. Foi também medida a área superficial de duas regiões diferentes dos corpos colados: uma próxima à interface com o molde de gesso, e outra correspondente à fatia central das pastilhas. A superfície de fratura das amostras coladas foi analisada por microscopia eletrônica de varredura (Leica/Cambridge - Stereoscan 440), para verificar-se o eventual efeito da distribuição granulométrica sobre gradientes de porosidade, morfologia e tamanho dos poros formados.

\section{RESULTADOS}

Curvas de Distribuição-Alvo

A Fig. 1 mostra as curvas de distribuição granulométrica para

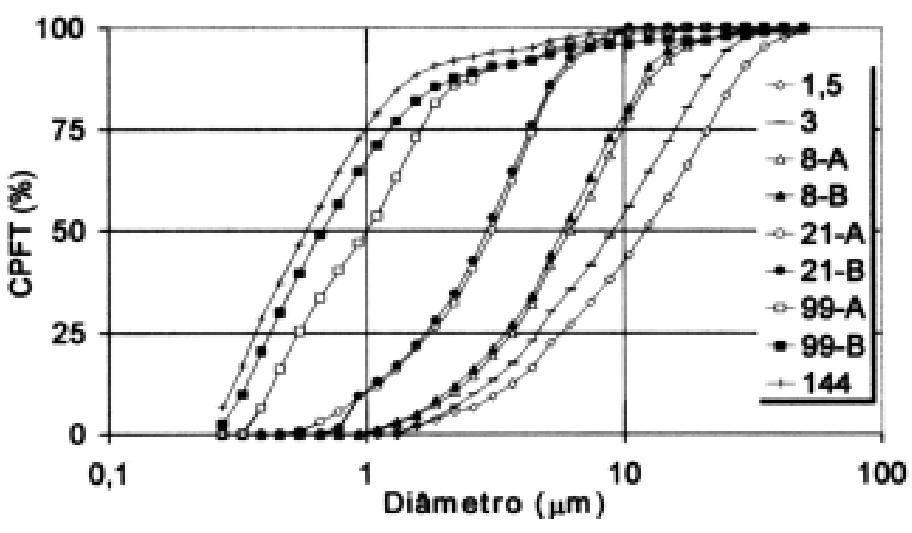

Figura 1: Curvas de distribuição de tamanho de particula para a alumina eletrofundida marrom submetida a diferentes tempos de moagem. $O$ número representa as horas de moagem, e as letras A e B designam diferentes lotes.

diferentes tempos de moagem da matéria-prima.

Com estes resultados, foram construídas as curvas de distribuição de Alfred e Andreasen com módulo de distribuição igual a 0,37 , segundo a metodologia descrita no procedimento experimental. Determinou-se que a combinação entre as matérias-primas deveria obedecer às proporções descritas na tabela $\mathrm{I}$.

Tabela I : Porcentagem de cada matéria-prima utilizada para obter as composições de Alfred e Andreasen com $q=0,37$.

\begin{tabular}{lll}
\hline Matéria-Prima & Alfred \% & Andreasen \% \\
\hline 1,5 & 76,0 & 63,0 \\
\hline $21 \mathrm{~A}$ & 4,0 & 0,0 \\
\hline $99 \mathrm{~A}$ & 10,0 & 0,0 \\
\hline $99 \mathrm{~B}$ & 10,0 & 0,0 \\
\hline 144 & 0,0 & 37,0 \\
\hline
\end{tabular}

As matérias-primas 3, 8A, 8B e 21B não foram selecionadas pelo software para compor a formulação.

As composições assim obtidas foram caracterizadas para verificar-se o grau de ajuste às curvas-alvo. Os resultados estão na Fig. 2.

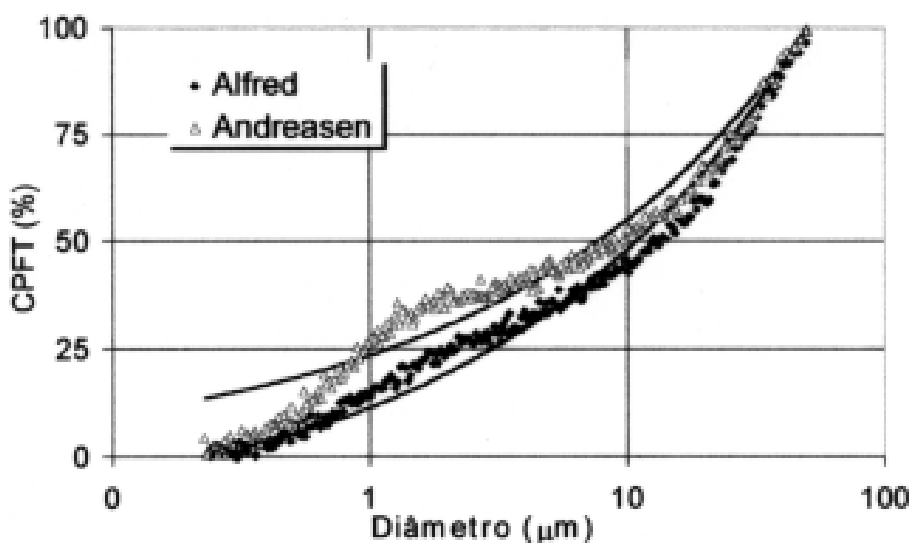

Figura 2: Curvas de distribuição granulométrica acumulada das amostras com distribuição de Alfred e de Andreasen, teóricas (linhas contínuas) e experimentais (símbolos), com módulo de distribuição $q=0,37$, obtidas pela combinação das diferentes matérias-primas. 
$\mathrm{Na}$ tabela II estão relacionados os valores da porosidade residual $\left(\mathrm{P}_{0}\right)$, calculados segundo o procedimento proposto por $\mathrm{Yu}$ e Standish [7] a partir das curvas de distribuição granulométrica experimentais e de área superficial específica dos pós obtidos.

Tabela II: Valores de Área Superficial Especifica (A. S. E.) e Porosidade Residual $\left(P_{0}\right)$ para as amostras com distribuição de Alfred e de Andreasen.

\begin{tabular}{lll}
\hline & Alfred & Andreasen \\
\hline A. S. E. $\left(\mathrm{m}^{2} / \mathrm{g}\right)$ & 4,76 & 7,54 \\
\hline $\mathrm{P}_{0} \%$ & 13,9 & 16,5 \\
\hline
\end{tabular}

\section{Propriedades do Compacto a Verde}

\section{Velocidade de Formação de Parede}

A espessura dos corpos obtidos pela colagem das suspensões em função do tempo é mostrada na Fig. 3, na qual se pode avaliar a velocidade de formação de parede de cada composição

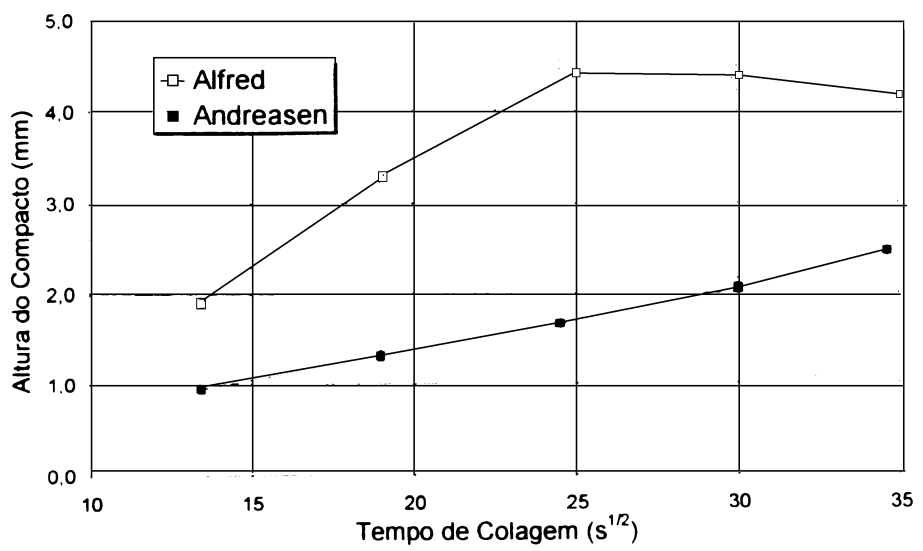

Figura 3: Velocidade de formação de parede das composições de Alfred e de Andreasen.

Verifica-se que para um tempo de colagem de até $25 \mathrm{~s}^{1 / 2}$ (10 minutos) a composição de Alfred apresentou velocidade de formação de parede maior que a de Andreasen, como se observa pela maior inclinação da reta neste intervalo. Entretanto, para tempos acima de 10 minutos não houve aumento na espessura do compacto, para a distribuição segundo Alfred

Quanto à composição de Andreasen, a velocidade de formação de parede foi constante ao longo do tempo. Não foi observado nenhum patamar de velocidade dentro do intervalo de tempo no qual o ensaio foi efetuado.

\section{Densidade a Verde e Distribuição de Tamanho de Poros}

Na Fig. 4 são mostradas as curvas de frequência de tamanho de poro das amostras com distribuição de Alfred e de Andreasen, obtidas através de prensagem uniaxial, prensagem isostática e colagem de barbotina.

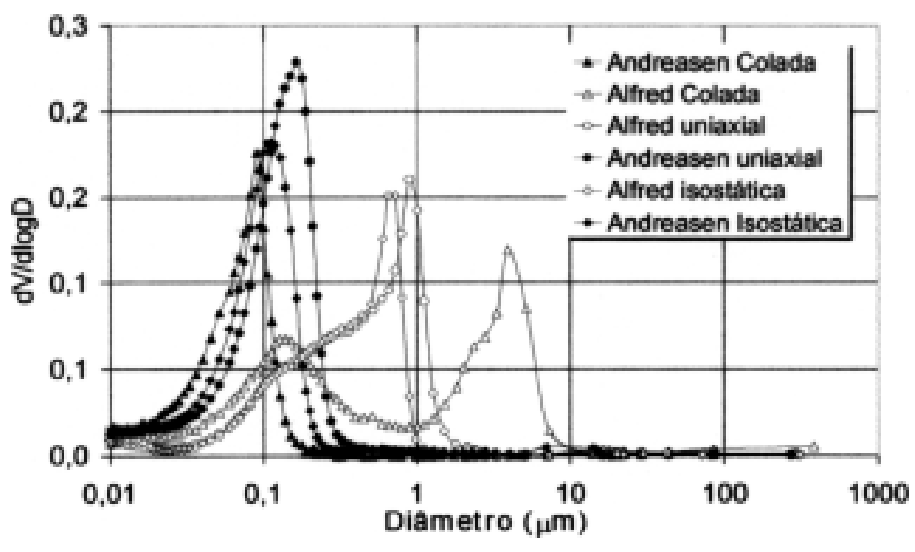

Figura 4: Curvas de freqüencia de tamanho de poro das amostras a verde de Alfred e de Andreasen obtidas por prensagem isostática (200 MPa), prensagem uniaxial (136 MPa) e colagem de barbotina.

Pode-se observar que a população de poros da amostra com distribuição de Alfred obtida por colagem apresentou uma distribuição bimodal bem definida, com picos de freqüência nos diâmetros de 4,0 $\mu \mathrm{m}$ e $0,13 \mu \mathrm{m}$. Nas amostras Alfred obtidas por prensagem, as distribuições de tamanho de poro foram muito semelhantes, e embora os picos de freqüência sejam menos definidos, é possível distinguir um aspecto bimodal. Quanto às amostras com distribuição de Andreasen, observa-se que todas elas apresentaram uma distribuição de tamanho de poros unimodal, com picos de freqüência bem definidos e localizados em uma mesma região, independentemente da técnica de processamento empregada.

Na Fig. 5 estão relacionadas as densidades a verde dos compactos produzidos a partir das duas composições estudadas, obtidos por diferentes métodos de compactação.

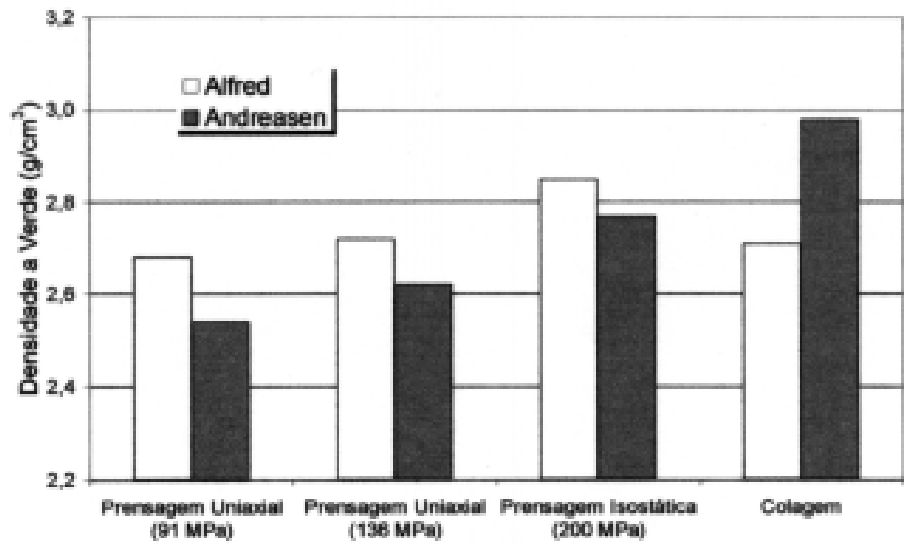

Figura 5: Densidade aparente a verde de corpos-de-prova produzidos com pós com distribuição de Alfred e de Andreasen, com módulo de distribuição 0,37, por diferentes métodos de compactação.

Na tabela III estão relacionadas as porosidades dos compactos originados a partir das duas composições estudadas, obtidos por porosimetria de mercúrio. Verifica-se que a amostra de Alfred apresentou uma porosidade total mais elevada que a de Andreasen apenas nas amostras obtidas por colagem. Este resultado é coerente com as medidas de densidade a verde (Fig. 5). 
Tabela III: Porosidade total dos compactos obtidos com as composições de Alfred e Andreasen, medidos por porosimetria de mercúrio.

\section{Porosidade Total (\%)}

\section{Amostra}

Alfred

Andreasen

Prensagem

28,81

30,56

uniaxial (136 MPa)

\section{Prensagem}

\begin{tabular}{lll} 
isostática $(200 \mathrm{MPa})$ & 21,16 & 27,10 \\
\hline Colagem & 30,44 & 22,61 \\
\hline
\end{tabular}

\section{Micrografias dos Compactos a Verde}

Na Fig. 6 são apresentadas as micrografias dos compactos a verde das composições de Alfred e Andreasen, junto à interface

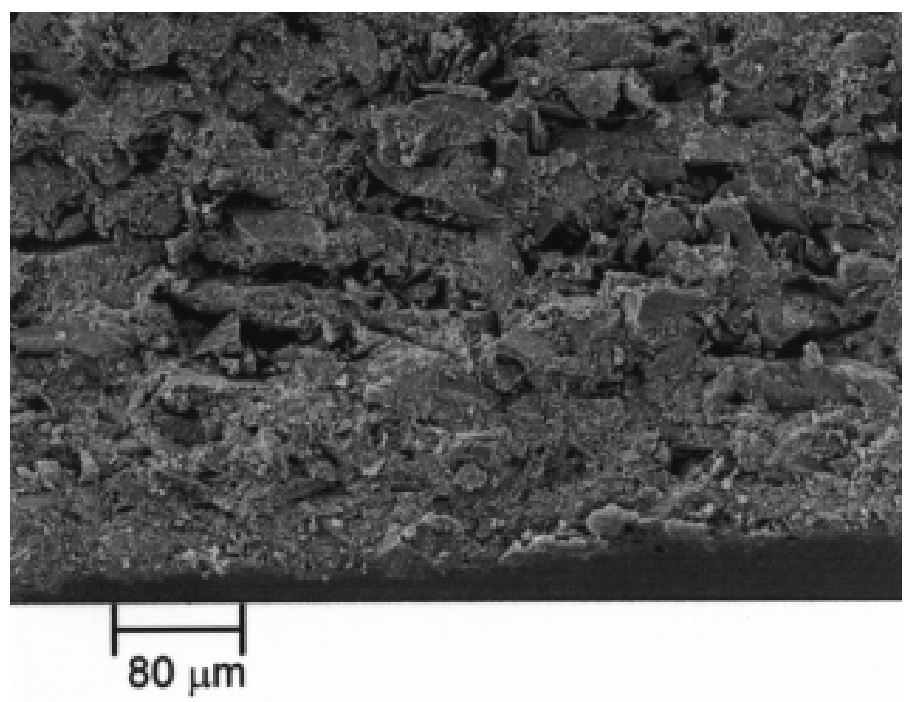

(a)

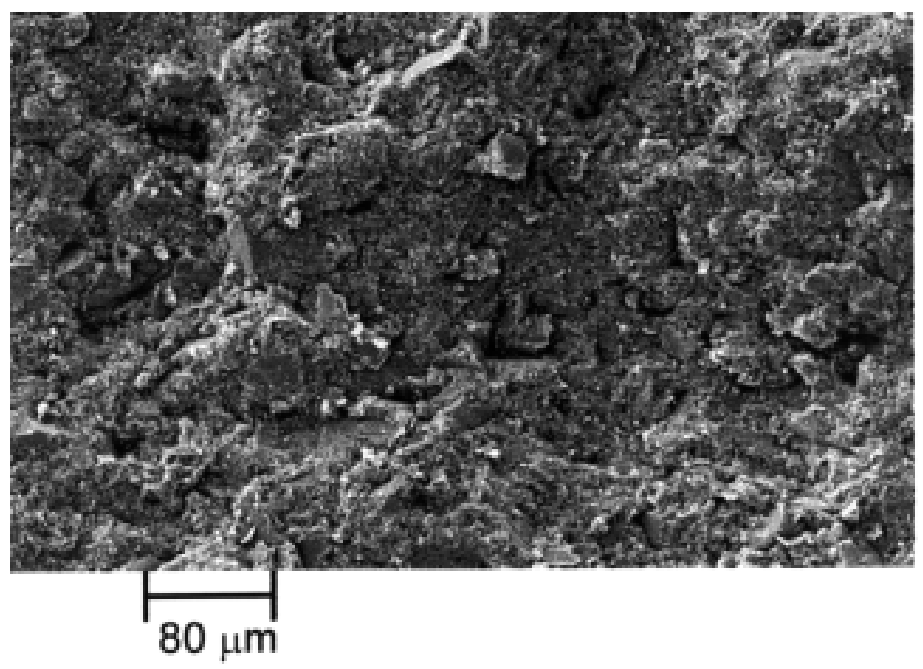

(b)

Figura 6: Micrografia obtida por microscopia eletrônica de varredura das amostras com distribuição de (a) Alfred e (b) Andreasen, na região de interface com a parede do molde de gesso (parte inferior da micrografia). com a parede do molde.

Observa-se que na amostra com composição de Alfred formouse uma região com alta densidade de empacotamento junto à parede do molde, ao passo que em regiões mais distantes desta interface observa-se maior porosidade. Na amostra de Andreasen, ao contrário, formou-se um compacto homogêneo com alta densidade de empacotamento. Neste sistema, não é possível identificar gradientes na densidade de empacotamento, ao menos nas espessuras obtidas.

\section{DISCUSSÕES}

\section{Porosidade das Formulações}

A metodologia proposta para se projetar composições com uma curva de distribuição de tamanho de partícula desejada foi bem sucedida, como se pode observar na Fig. 2. Os desvios percentuais médios ficaram em torno de 3 a $4 \%$, sendo que o desvio médio um pouco mais elevado para a composição de Andreasen deveu-se à inexistência de partículas infinitamente pequenas, o que não é previsto no modelo teórico.

Na Fig. 7 mostra-se um gráfico com a distribuição discreta de tamanho de partículas das composições de Alfred e de Andreasen, teóricas e experimentais, construído a partir da Fig. 2.

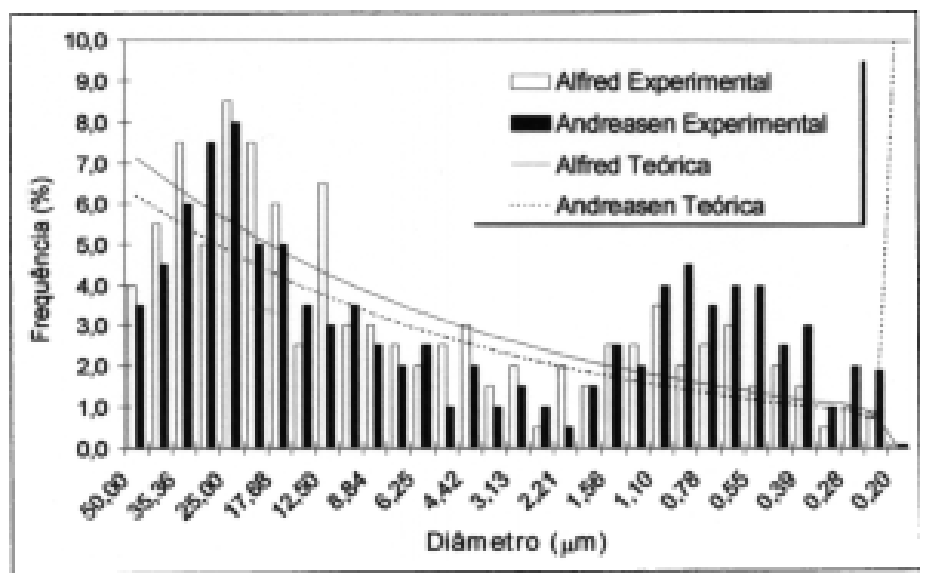

Figura 7: Distribuições discretas de tamanho de partículas das amostras de Alfred e Andreasen, teóricas e obtidas experimentalmente.

Ambas as amostras apresentaram desvios da curva experimental em relação à teórica. Estes desvios, embora pequenos (3 a $4 \%$ ), têm sua origem relacionada primordialmente à impossibilidade de se conseguir um ajuste perfeito com as distribuições granulométricas das matérias-primas disponíveis, uma vez que foram utilizadas matérias-primas com distribuições contínuas, e eventualmente a erros devidos a limitações da técnica de caracterização utilizada. De fato, a lei de Stokes, na qual se baseia o equipamento de caracterização empregado no presente trabalho (Sedigraph5100), não é capaz de descrever adequadamente a sedimentação de partículas abaixo de $1 \mu \mathrm{m}$, uma vez que estas são significativamente afetadas pelo movimento browniano e por correntes de convexão presentes na suspensão [6].

Em uma distribuição de Alfred com q = 0,37, a qual é projetada para maximizar a densidade de empacotamento, os poros existentes no compacto seriam atribuídos, idealmente, apenas aos vazi- 
os residuais $\left(\mathrm{P}_{0}\right)$ decorrentes da existência de um tamanho mínimo de partículas no sistema, os quais não são preenchidos devido à inexistência de partículas ainda menores. Deste modo, o volume aparente da amostra seria dado por :

$$
\mathrm{V}_{\mathrm{ap}}=\frac{1}{1-\mathrm{P}_{0}}
$$

O volume aparente é determinado basicamente por um conjunto de partículas contidas em uma faixa de tamanho, denominada "mistura de controle" [7]. No caso do modelo de Alfred com q= 0,37, a mistura de controle é constituída por partículas mais grossas que no modelo de Andreasen com q =0,37.

Quando a mistura de controle apresenta uma estrutura de empacotamento diferente da ideal, há um aumento do volume aparente do sistema, e portanto, da porosidade. Isto é o que ocorre nos processos de conformação convencionais, os quais não são capazes de fazer com que a máxima compactação possível de um pó seja atingida. Assim, o volume aparente dos compactos, dado pela mistura de controle, nunca atinge seu valor mínimo. Como nas amostras de Alfred a mistura de controle é dada por partículas maiores, deficiências no empacotamento causam a formação de poros igualmente maiores. Na amostra de Andreasen, ao contrário, a mistura de controle é dada por partículas finas, e portanto, imperfeições no empacotamento dos poros geram poros pequenos.

Na Fig. 4 observa-se claramente nas amostras com distribuição de Alfred a população de poros residuais na faixa próxima a $0,15 \mu \mathrm{m}$. Esta característica esteve presente em todas as amostras, independentemente da técnica de compactação empregada. Verifica-se também a existência de poros maiores, devidos a problemas de compactação, cuja localização variou segundo o processamento.

Ainda na Fig. 4, observa-se uma única população de poros nas amostras com distribuição de Andreasen, constituída pela soma de poros residuais e de poros resultantes de falhas de compactação. Neste sistema, perturbações no empacotamento da mistura de controle, constituída por partículas finas, causou apenas um aumento no volume aparente da amostra, sem originar uma segunda população de poros.

\section{Densidade do Compacto a Verde em Função do Processamento}

$\mathrm{Na}$ tabela II nota-se que o valor de $\mathrm{P}_{0}$, calculado a partir das curvas experimentais de distribuição de tamanho de partícula, foi menor para o pó com distribuição de Alfred, indicando que este pó é capaz de originar compactos de maior densidade. De fato, na Fig. 5 observa-se que nos compactos obtidos por prensagem a densidade das amostras com distribuição de Alfred foi sempre maior que a dos compactos com distribuição de Andreasen. Isto pode ser atribuído à distribuição granulométrica, a qual favorece um maior empacotamento de partículas, conforme mostrou o valor de $\mathrm{P}_{0}$, associado a um maior valor de área superficial da amostra de Andreasen, a qual aumenta o número de pontos de contato entre as partículas, e portanto, a fricção interna do sistema, dificultando uma boa compactação por prensagem.

Nos corpos colados, entretanto, verifica-se que enquanto a amostra com distribuição de Andreasen alcançou a maior densidade dentre todas as amostras produzidas, a amostra de Alfred apre- sentou uma densidade sensivelmente menor.

Este resultado mostra que na colagem, a mistura de controle da amostra de Andreasen, constituída por partículas finas, alcançou uma alta densidade de empacotamento, enquanto que a mistura de controle da amostra de Alfred, constituída por partículas mais grossas, constituiu uma estrutura com empacotamento pior.

A razão deste comportamento está relacionada muito provavelmente às diferentes quantidades de finos das amostra de Alfred e Andreasen. Quanto menor o tamanho de partícula, maior a influência das forças decorrentes de fenômenos superficiais. A maior espessura relativa da dupla camada elétrica nas partículas finas, associada à baixa velocidade de formação de parede favorece o posicionamento das mesmas segundo um arranjo mais ordenado no compacto. Nas partículas maiores, ao contrário, as arestas e o formato irregular, associados à alta velocidade de formação de parede dificultam movimentos de rotação, e portanto, a acomodação do sistema, o que favorece a formação de uma estrutura mais aberta. Daí a menor densidade de empacotamento dos compactos com distribuição de Alfred conformados por colagem, uma vez que estas partículas constituem a mistura de controle. Resultado semelhante foi encontrado por Smith e Harber [5], em trabalho no qual verificaram que uma amostra com distribuição de Alfred e módulo de distribuição de 0,37 apresentou uma população bimodal de poros, com picos de porosidade localizados em $1 \mu \mathrm{m}$ e $0,1 \mu \mathrm{m}$, e alta velocidade de formação de parede. No trabalho citado [5], à medida que a quantidade de partículas finas aumentou houve formação de uma única população de poros, na faixa de $0,1 \mu \mathrm{m}$ e diminuição na velocidade de formação de parede, resultado este bastante similar ao da composição de Andreasen estudada no presente trabalho.

\section{Arraste e Percolação de Partículas}

Observando-se a micrografia na Fig. 6 (a) observa-se a existência de um gradiente de empacotamento na direção em que ocorreu a colagem. Este gradiente formou-se, muito provavelmente, devido à percolação de partículas finas através da estrutura de poros do compacto, no decorrer da colagem [8]. Conforme foi discutido no item anterior, falhas na compactação na mistura de controle de pós com a distribuição de Alfred causam a formação de uma população de poros grandes. No processo de colagem de barbotina, estes poros foram suficientemente grandes para permitir que o fluxo de água através do compacto, no decorrer da colagem, fosse capaz de arrastar partículas pequenas, retirando-as de suas posições originais, e depositando-as na interface com o molde. Muito provavelmente, este processo contribuiu para que a população de poros grandes das amostras coladas tenha tido um diâmetro maior que o das amostras prensadas, já que a remoção das partículas finas deixa vazios nas suas posições originais.

Na Fig. 6 (a) observa-se o resultado da movimentação de partículas finas, que causou, na amostra de Alfred, a deposição de uma camada destas partículas na região próxima à parede do molde. Nas regiões mais afastadas da interface é possível observar os poros grandes, através dos quais as partículas finas se movimentaram. Já na Fig. 6 (b) o compacto é homogêneo em toda a amostra, e gradientes de compactação não são observados.

A variação na velocidade de colagem é outra conseqüência desta movimentação de partículas finas. Observando-se novamente a Fig. 3, nota-se que até um tempo de 10 minutos $\left(25 \mathrm{~s}^{1 / 2}\right)$ a velocidade de formação de parede da amostra com distribuição de Alfred 
foi mais elevada que a da amostra com distribuição de Andreasen. Isto é atribuído à maior permeabilidade do compacto em formação, devido à população de poros grandes. A partir de 10 minutos a espessura da parede desta amostra torna-se constante, devido à deposição das partículas finas junto à parede do molde, constituindo uma camada com alta densidade de empacotamento, e portanto, baixa permeabilidade. Na amostra com distribuição de Andreasen a existência apenas de poros pequenos tornou a percolação de partículas finas impossível, e conferiu uma permeabilidade mais baixa ao compacto. Como conseqüência, a espessura de parede aumentou regularmente, e com uma velocidade menor, resultando em um compacto mais homogêneo.

\section{CONCLUSÕES}

Conclui-se que o modelo de Alfred, ao admitir conceitualmente a existência de um tamanho mínimo de partícula, torna-se potencialmente capaz de produzir compactos com maior densidade que o modelo de Alfred. Entretanto, não considera que os métodos de compactação convencionais proporcionam compactos em que ocorrem flutuações na densidade de empacotamento, gerando uma população de poros maiores que os poros intersticiais. Esta população de poros grandes pode ser de difícil eliminação durante a sinterização, introduzindo defeitos no produto final. Em processos de conformação via úmida nos quais um fluxo de água esteja envolvido, como colagem de barbotina e filtro-prensagem, esta característica pode também acarretar problemas decorrentes da percolação de partículas finas, como queda de permeabilidade e diminuição na densidade a verde do compacto.

No modelo de Andreasen o excesso de partículas finas, diminui a densidade de empacotamento deste sistema. Por outro lado, este excesso é capaz de contrabalançar flutuações no empacotamento decorrentes do processo de conformação, gerando uma única população de poros intersticiais de fácil eliminação durante a sinterização. A elevada área superficial decorrente do maior número de partículas finas pode dificultar a obtenção de um compacto denso, devido à elevada fricção interna. Ainda, o reduzido tamanho dos poros intersticiais formados no compacto a verde diminui a permeabilidade do compacto.

Conclui-se, portanto, que embora o modelo de Alfred seja conceitualmente mais realístico, não pode ser considerado como um modelo definitivo de empacotamento de partículas. A escolha do modelo de empacotamento mais adequado deve levar em consideração características intrínsecas a cada processo de conformação, como a existência ou não de um fluxo de água ao longo do compacto; o nível e o tipo de pressão (uniaxial ou isostática) que será aplicado, no caso de prensagem a seco; o grau de mobilidade das partículas no decorrer do processo (este é elevado, por exemplo, nos processos de conformação fluida, sendo menor na extrusão, e ainda menor na prensagem a seco), o qual está diretamente relacionado a flutuações na densidade no compacto a verde; a adequação da temperatura de queima à eliminação dos poros existentes nos compactos. A consideração destes fatores pode também vir a requerer a adoção de módulos de distribuição diferentes de $\mathrm{q}=$ 0,37, como vem sendo verificado em outros trabalhos desenvolvidos por este grupo.

\section{AGRADECIMENTOS}

Os autores agradecem o suporte oferecido pela ALCOA alumínio S. A., CNPq, CAPES e FAPESP na realização deste trabalho.

\section{REFERÊNCIAS}

[1] R. K. Mc Geary, Mechanical Packing of Spheroidal Particles. J. Am. Ceram. Soc., 44 (1961) 513-522.

[2] J. E. Funk, D. R. Dinger, Particle packing, part I-fundamentals of particle packing monodisperse spheres. Interceram,. 41, 1 (1992) $10-14$

[3] J. E. Funk, D. R. Dinger, Particle Packing, Part VI-Applications of Particle Size Distribution Concepts. Interceram, 43, 5 (1994) 350-3.

[4] P. A. Smith, R. A. Harber, Effect of Particle Packing on the Filtration and Rheology Behaviour of Extended Size Distribution Alumina Suspension, J. Am. Ceram. Soc., 78, 7 (1995) 1737-1744. [5] P. A. Smith, A. G. Haerle, Particle Crowding Analysis of Slip Casting, J. Am. Ceram. Soc., 78, 3 (1995) 809-812.

[6] T. Allen, R. Davies, Modern Aspects of Particle Size Analysis, Advances in Ceramics, Vol.21: Ceramic Powder Science, 1987.

[7] A. B. Yu, N. Standish, Estimation of the Porosity of Particle Mixtures by a Linear-Mixture Packing Model, Ind. Eng. Chem. Res., 30 (1991) 1372-1385.

[8] J. H. D. Hampton, B. S. Savage, R. A. L. Drew, Experimental Analysis of Fine-Particle Migration during Ceramic Filtration Processes. J. Am. Ceram. Soc., 75, 10 (1992) 2726-2732.

[9] R. G. Pileggi, Efeito da distribuição granulométrica sobre o comportamento reológico de concretos refratários, Dissertação de Mestrado, UFSCar, DEMa, PPG-CEM, 1996, 210 p. 